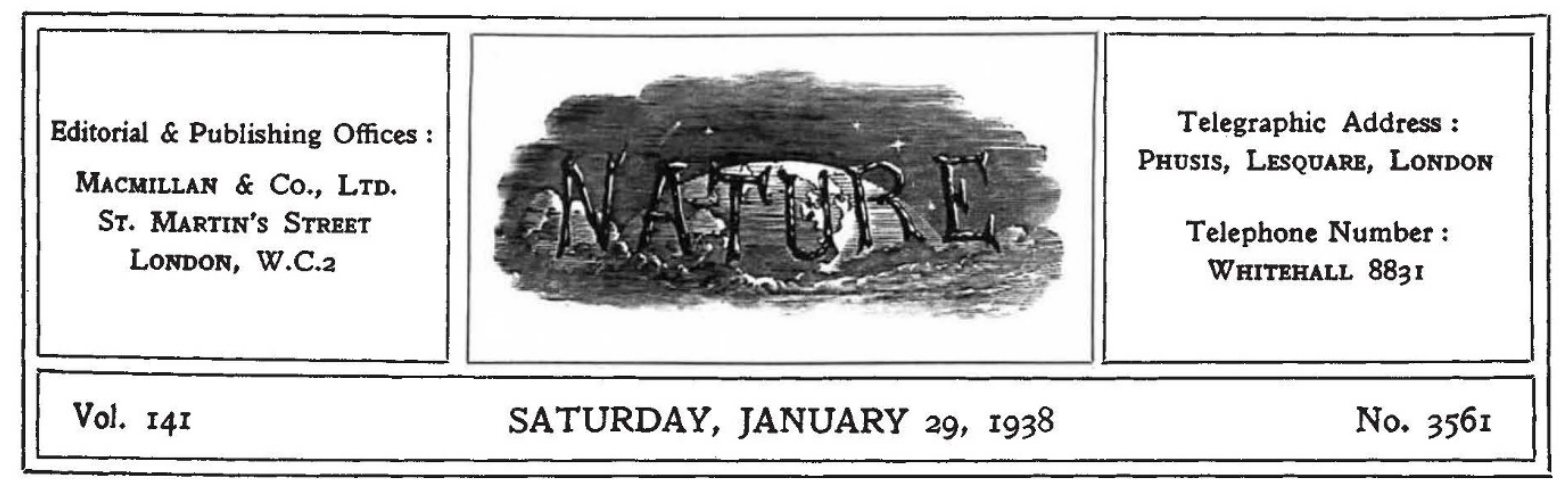

\title{
Ethnographical Museums and Empire
}

$\mathrm{I}^{\mathrm{N}}$ $\mathrm{N}$ a lecture delivered recently before a joint meeting of the Royal Society of Arts and the India Society by Mr. J. de La Valette (see NATuRE, Dec. 25, p. 1108) attention was directed to the work of the museums of Holland in promoting the study of the indigenous cultures of the Dutch possessions in Indonesia, and their aim of making familiar to the Dutch people the conditions of native life in these remote parts of the world, for the administration of which they themselves are ultimately responsible. In its broader aspect the problem with which those who have organized these museums have been confronted is one obviously of special interest to Great Britain, where there is a like need for general understanding of alien peoples and cultures under one and the same imperium, but on a vastly extended scale.

Mr. de La Valette pointed out that in their method of approach to the problem of the arrangement and organization of an ethnographical museum demonstrating the mode of life of their dependencies, the Dutch are in harmony with the modern tendency towards a 'humanism' in anthropological studies, in which the various disciplines of the study of man-ethnology, physical anthropology, archæology, history and the like-set apart for academic purposes in the past, are once more brought together and focused on the study of a single integrated group or culture. Man, his works and his environment, are thus studied as a single and unified whole and not in water-tight compartments. Mr. de La Valette then went on to contrast with these methods the antiquated procedure, as he sees it, of the museums of Great Britain; he admitted that they are unrivalled in the extent and variety of their collections, but, he maintained, dominated by a Victorian tradition of specimen-collecting and a passion for classificatory arrangement, which sterilizes them of all life and meaning in relation to the cultural history of man in its specific manifestations.

In directing attention to the merits of this regional or unitary method of museum organization in ethnographical studies, in which the whole life of a group is displayed as a rounded whole, Mr. de La Valette raised a question to which in its wide ramifications it is difficult to set limits of discussion. He was also in the strong tactical position of addressing an audience the interests of which in the main were directed to a single area, India - which is none the less concentrated though it is a sub-continent comprising not one but many ethnic, cultural and regional units. On the general question, however, this much may be said. In so far as the aim of the Dutch museums has been to bring home to their people an understanding of the life of their subject populations by intensive illustration, it is in accord with anthropological opinion in Great Britain, where the advantage to the British people of an ethnographical museum demonstrating the life and modes of thought of the peoples of alien culture of the dominions and dependencies has long been urged. Close on forty years ago Mr. (later Sir) Hercules Read, keeper of the Ethnographical Department of the British Museum, advocated in the strongest terms the establishment of an Imperial Bureau of Anthropology in connexion with his department, and time and again since then the need of an imperial ethnographical museum has been urged as the best, if perhaps not the only, means of promoting an educated interest among the general public in our dependent and fellow-subjects of culture other than our own.

While it is probable that there would be no two opinions as to the desirability, not to say the 
urgency, of establishing an imperial ethnographical museum, the choice of method of arrangement and organization is not without its difficulties. There can be no question that in so far as these should be determined by the instructional aim, the regional and unitary method of display is ideal. Practical considerations, however, have to be taken into account; and whereas in Holland the problem has proved open to solution, in dealing with the native peoples of the British Empire provision would have to be made for a very different set of conditions. The Dutch possessions in Indonesia cover an environment limited in range; the cultures and ethnic groups relatively are neither numerous nor on the whole widely diverse in character. In the British dominions, on the other hand, the range in environment, in ethnic and cultural contrast, is world-wide. As a concrete proposal a scheme of intensive display, such as has been introduced in Holland, on a scale commensurate to the British Empire, would be wrecked at its inception by financial considerations alone. On the other hand, there is no adequate reason why certain larger units such as Africa and India, which lend themselves to a modified unitary treatment, should not receive special consideration and be the subject of intensive display.

Curators of existing collections in Great Britain will no doubt have received Mr. de La Valette's criticisms with very mixed feelings. They themselves are their sternest critics, and not all are wedded to tradition. But the museum curator perhaps more than any other research worker, is firmly circumscribed by conditions; and the history and character of the collections, as well as the space available, limit the freedom with which problems in display may be solved.

Notwithstanding the aspersion of specimencollecting cast upon our museums, it must be remembered that many of the exhibits are on historic interest in themselves as commemorative of early exploration, and could not be withdrawn from exhibition without loss of interest. Such, for example, are many exhibits from the Pacific in the British Museum, especially those acquired by Capt. Cook, or some of the early material from America. This brings us to the most serious point in Mr. de La Valette's indictment of museum policy in Great Britain. He alludes to a proposal to break up and distribute among other institutions in South Kensington the collections which, as the Indian Museum, form part of the Victoria and Albert Museum. These collections have as their nucleus the historic collection which belonged to the Honourable East India Company, a collection which embodies a stirring page in British history. Becoming the property of the Government after the Mutiny, it was transferred in 1870 to the Science and Art Department, later absorbed in the Board of Education when that body was formed. It thus became part of the Victoria and Albert Museum. Recently, under a new curator, Mr. K. de B. Codrington, the collections have undergone, or rather are undergoing, a process of rearrangement and selection, which departs from the rsthetic prepossession of the major collection in favour of a grouping of interests to give as full and as educative a picture as possible of India's national culture as a whole in its historical and geographical setting. Consternation aroused by this proposal to destroy what all who have examined it with any care must agree is a brilliant essay in museum arrangement on scientific and educational lines, has to some extent been allayed by an assurance received by Sir Francis Younghusband, as president of the India Society, that the collections will not be distributed, but will remain as a part of the Victoria and Albert Museum.

Satisfactory as this may seem, it is questionable whether it goes far enough. Is it to be assumed that provision will be made for the expansion which will be necessary to carry out fully the scheme now in progress of development? Unless the present divorce of antiquity from historic times is to continue, it is difficult to see how adequate provision for a satisfactory display of Indian culture can be made short of a much enlarged museum. For not only are the antiquities of the original collections, including many valuable examples of early Buddhist art, still housed at the British Museum, although the property not of the trustees of that institution, but of the Secretary of State for India, but also the span of time to be covered now goes back to the beginning of the third millennium B.c. in the civilization of the Indus valley. Further, geographically, Indian cultural study now leaps the barrier of boundaries to extend half over Asia, from Irak to Central Asia, China, Japan, Further India and Indonesia, so far as Bali and distant Celebes. The material available in the national collections-the Aurel Stein collections from Central Asia alone are unique as documentary evidence for the spread of Buddhist art and Indian influence-if brought together under one roof, would demonstrate 
Indian culture in a manner possible nowhere else among the collections of the world, even in India itself.

On the grounds of public policy, the formation of a museum of Indian life and culture cannot be too strongly urged. Now that the bonds of Empire have become tenuous indeed, we hold India by a thread. But impalpable bonds, as has been shown by the visit of the British Association delegation to the jubilee meeting of the Indian Science Congress Association this month, can be made stronger than any material force. To the degree in which our future policy towards India is rooted in an understanding of Indian aspirations on the part of the British people, the greater the strength of the bond that will hold this great country within the Empire. A great Indian cultural museum would certainly contribute the major part to such an understanding. It would show that whatever the differences between the two peoples may be, to India belongs a civilization older than our own, which in art and intellectual accomplishment has been in no way our inferior, while in Buddhism it has produced a creed which more nearly than any other in the world's history approaches the way of life inculcated by Christianity.

\section{Principles of Biological Control}

The Biologic al Control of an Insect in Fiji An Account of the Coconut Leaf-mining Beetle and its Parasite Complex. By T. H. C. Taylor. Pp. $239+23$ plates. (London: Imperial Institute of Entomology, 1937.) n.p.

$\mathrm{W}^{\circ}$ ORKERS in the field of applied science are often reproached by their academic colleagues engaged in pure science with their failure to publish their methods and results and with the sketchy and inadequate character of what they do publish. This complaint is based, to some extent at least, on a misunderstanding of the object of applied science, which is not, primarily, the discovery of truth, but simply the production of facts. We call in the medical man to cure our rheumatism, and the builder to put up our house. We do not expect them to write monographs on these subjects, und we should feel rather dissatisfied if we found that they were doing this instead of getting on with the job for which we paid them. A certain continuous pressure brought to bear on the economic worker often prevents him effectively from exploiting the scientific byproducts of his work; and in some cases this pressure is probably both necessary and justifiable.

On the other hand, it is clear that there are vast fields of applied science in which such effective practical rules as have been worked out in medicine and bricklaying do not yet exist, where almost every conceivable practical operation is at the same time a scientific experiment, on the result of which further progress depends. In such cases, it may be impossible to draw any lesson from the work done unless the methods used and the consequence of resultant events are recorded in detail. Furthermore, though there is not necessarily any connexion between the power of doing something well and the ability to explain how it is done, it does seem that, for the full comprehension of data, explanation carried to the point of actual exposition is highly desirable. Writing up our facts for publication helps us to realize not only what we know, but also, and even more important, what we do not know.

Work on the biological control of insect pests, which is applied entomology of the most difficult and complex description, has suffered a good deal in the past, and still suffers, from the fact that scientific analysis has not kept pace with practical experiment. Great operations have been carried out in certain parts of the world of which we can scarcely say whether they have succeeded or failed, to say nothing of specifying the reasons for failure and success. Attempts have been made in recent years to deal with some of the problems of biological control by mathematical methods; but, interesting and suggestive as they are, it is only too obvious that they can never replace the observation of actual events and indeed, the investigations carried out by workers like Salt, Lloyd, Ullyett, Walker and others on the problem of host selection nave made amply clear the defects of the concepts embodied in the basic equations of our mathematical theories. Fundamental work on a large scale is urgently required and although, as was pointed out in NATURE of February 20, 1937 (p. 304), the authorities concerned with operations in biological control in the British Empire have not yet provided for it, satisfactory progress cannot be made until the need is met.

In these circumstances, we feel sure that every student of biological control will heartily welcome Dr. T. H. C. Taylor's fascinating monograph on 